05

\title{
Конструкционные прочностные параметры и разрушение ультрамелкозернистого титана Grade 4, полученного методом равноканального углового прессования РКУП-К
}

\author{
(C) И.В. Смирнов
}

Санкт-Петербургский государственный университет, 199034 Санкт-Петербург, Россия

e-mail: i.v.smirnov@spbu.ru

(Поступило в Редакцию 11 июля 2018 г.)

Обработка металлов и сплавов интенсивной пластической деформацией (ИПД) влечет измельчение зеренной структуры материалов, что может приводить к их повышенным физико-механическим свойствам, например, уникальной прочности на разрыв. Однако исследование механических свойств материалов после обработки ИПД обычно ограничивается испытанием на растяжение, а другие характеристики прочности и разрушения остаются без должного внимания. Представлены результаты экспериментальных исследований предельной прочности на разрыв, ударной вязкости, трещиностойкости, а также соответствующие поверхности разрушения исходного и ультрамелкозернистого чистого титана Grade 4, который был получен методом непрерывного равноканального углового прессования. Результаты показали, что при высокой предельной прочности на разрыв материала после обработки ИПД он проявляет пониженные характеристики сопротивления старту и распространения трещины при однократном нагружении. Поверхность разрушения обоих состояний структуры титана демонстрирует преимущественно локализованную пластическую деформацию.

DOI: 10.21883/JTF.2019.04.47309.266-18

\section{Введение}

Титан и его сплавы обладают универсальными конструкционными свойствами, что делает их ключевыми материалами для таких стратегических областей как авиастроение и ракетостроение, судостроение, медицина и др. Однако бурное развитие упомянутых областей влечет постоянное изменение требований к конструкционным материалам. Повышаются требования к прочности и долговечности материала, а также экономичности его массового изготовления и обработки.

Одним из способов повышения механических свойств металлов и сплавов является формирование в них наноструктурного состояния [1-3]. Обеспечение нанокристаллической (менее $100 \mathrm{~nm}$ ) и ультрамелкозернистой $(100-1000 \mathrm{~nm})$ структуры, а также наличие нанодвойников, наночастиц и сегрегаций может приводить к повышенным прочности и пластичности, усталостной прочности, коэффициенту температурного расширения, магнитным свойствам и др. [2,3]. Выявление оптимальных взаимосвязей между свойствами материала и его наноструктурным состоянием входит в число наиболее актуальных направлений исследований в современном материаловедении.

Можно выделить два основных подхода к получению материалов с наноструктурой [4,5]. Первый, так называемый подход „снизу-вверх“, основан на выстраивании материала частицей за частицей, слоем за слоем, а также компактировании нанопорошков и наночастиц. Второй — „сверху-вниз“ - основан на измельчении микроструктуры материала до наноразмеров. Такой подход получил наибольшее распространение, так как поз- воляет получать более объемные и „чистые“ образцы материалов.

Измельчение зерна материала проводится с помощью методов интенсивной пластической деформации (ИПД) [3,6]. К методам ИПД относятся различные способы обработки металлов давлением с обеспечением высоких степеней деформации в материале: многократная ковка, экструзия, прокатка и др. Однако такие традиционные методы обработки металлов давлением не обеспечивают получение однородной нано- и ультрамелкозернистой (УМЗ) структуры, необходима еще большая степень истинной деформации $(\geq 4)$. На сегодняшний день наиболее популярными методами получения нанои УМЗ-металлов связаны с их обработкой по схеме равноканального углового прессования (РКУП) [6,7] и интенсивной пластической деформации кручением (ИПДК) [8].

Для оценки потенциального применения УМЗ и наноструктурных материалов необходимо как определение их прочностных характеристик, так и исследование процессов разрушения. Формирование УМЗ-структуры в титане и его сплавах с помощью методов ИПД позволяет существенно повысить его предел прочности на разрыв и предел текучести $[9,10]$. Однако в большинстве работ по этой тематике основное внимание посвящено исследованиям связи только этих механических параметров титана с режимами ИПД и формируемой структурой. Процессы разрушения и характеризующие его параметры как трещиностойкость, ударная вязкость и др. остаются малоизученными [11-13]. При этом ряд немногочисленных работ говорит о сравнительно низких способностях материалов после ИПД-обработки 
Таблица 1. Химический состав титана марки Grade 4 согласно сертификату производителя (в \%)

\begin{tabular}{ccccccc}
\hline $\mathrm{Ti}$ & $\mathrm{C}$ & $\mathrm{Fe}$ & $\mathrm{N}$ & $\mathrm{H}$ & $\mathrm{O}$ & др. примеси \\
\hline Основное & 0.05 & 0.15 & 0.007 & 0.0021 & 0.36 & $<0.3$
\end{tabular}

сопротивляться старту и распространению трещины, что связывается с низкой пластичностью материала.

В настоящей работе помимо предельной прочности на разрыв рассматриваются такие важные характеристики прочности, как трещиностойкость и ударная вязкость, а также соответствующие поверхности разрушения УМЗ титана Grade 4, полученного методом непрерывного равноканального углового прессования (РКУП-К), по сравнению с его крупнозернистым аналогом. Рассматриваемый УМЗ-материал $[14,15]$ имеет не только высокую прочность, но и пластическую деформацию, которая считается допустимой для стандартного крупнозернистого материала. В связи с небольшим объемом получаемых заготовок УМЗ-материала испытания проводились на миниобразцах.

\section{1. Материал и методики исследований}

Исследования проводились на технически чистом титане марки Grade 4 (табл. 1), производитель компания Dynamet (США). Исходный материал был поставлен в виде горячекатаных стержней диаметром $12 \mathrm{~mm}$.

Для формирования УМЗ-структуры исходный стержень был подвергнут обработке ИПД. Обработка материала проводилась в Уфимском государственном авиационном техническом университете (УГАТУ). Предварительно заготовка отжигалась $1 \mathrm{~h}$ при $680^{\circ} \mathrm{C}$. ИПД осуществлялась методом равноканального углового прессования по схеме Конформ (РКУП-К) [7] с 6-ю проходами (маршрут $B_{C}$ ) при угле пересечения каналов $120^{\circ}$ и температуре $200^{\circ} \mathrm{C}$. Конечная истинная степень деформации составила $\sim 4$. После ИПД заготовка подвергалась отжигу при $250^{\circ} \mathrm{C} 1 \mathrm{~h}$ и последующему волочению при диаметре фильер $12 \mathrm{~mm}$. Такая комбинация режимов обработки позволяет получить УМЗ титан Grade 4 с высокой прочностью и с наибольшей пластичностью, а также обеспечить однородность механических свойств по объему стержня $[14,15]$.

Однородность материала по объему стержня проверялась по измерениям микротвердости в трех произвольно выбранных продольных (длина $10 \mathrm{~mm}$ ) и поперечных сечениях. Измерение микротвердости по Виккерсу проводилось с помощью микротвердомера Shimadzu HMV G21DT с шагом $1 \mathrm{~mm}$.

Плотность материала определялась с помощью методики гидростатического взвешивания. Скорость распространения упругой продольной волны определялась с помощью оптико-акустической методики [16].

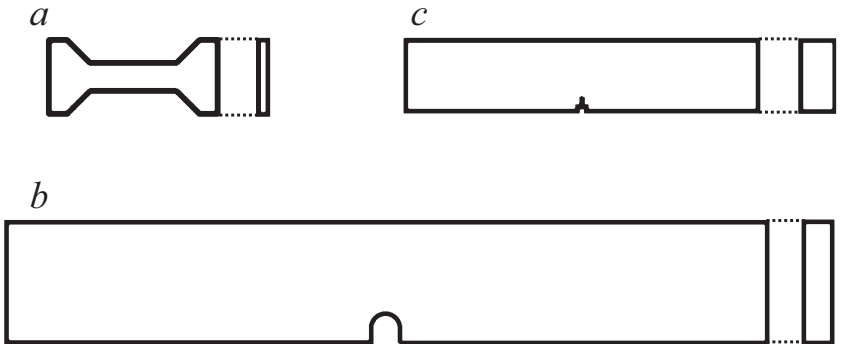

$10 \mathrm{~mm}$

Рис. 1. Форма и соотношение образцов: $a-$ растяжение; $b-$ ударная вязкость; $c$ - трещиностойкость.

Поскольку экспериментальные установки РКУП не позволяют производить заготовки достаточно больших размеров, все испытания проводились на миниобразцах. Образцы вырезались из стержня с помощью электроэрозионного станка, при этом наибольшая длина образца соответствовала продольному направлению стержня (рис. 1). Поверхность образцов полировалась до этапа суспензии с размером частиц не более $1 \mu \mathrm{m}$. Для подтверждения повторяемости результатов рассматривалось не менее трех образцов для каждого типа испытаний.

Испытания на одноосное растяжение проводились на испытательной машине Shimadzu AG-50kNX при скорости деформации образца $5 \cdot 10^{-5} 1 / \mathrm{s}$. Образцы имели форму лопаток (рис. 1) с размерами рабочей части $6 \times 1.7 \mathrm{~mm}$ и толщиной $0.8 \mathrm{~mm}$.

Испытания на ударную вязкость проводились по методу Шарпи на башенном копре Instron CEAST 9350 coгласно стандарту ГОСТ 9454 [17] на образцах с $U$-образным вырезом. Такой вырез рассматривается при выборе или приемо-сдаточных испытаниях металлов и сплавов. Образцы имели размеры допускаемые стандартом: длина $55 \mathrm{~mm}$, высота 8 (рабочая 6) $\mathrm{mm}$, ширина $2 \mathrm{~mm}$, радиус закругления $1 \mathrm{~mm}$. Скорость в момент удара составляла $5 \mathrm{~m} / \mathrm{s}$, что соответствовало энергии удара $\sim 68 \mathrm{~J}$.

Испытания на трещиностойкость проводись по схеме трехточечного изгиба на испытательной машине Instron ElectroPuls E3000 согласно стандарту ASTM 1820 [18]. Образцы были изготовлены в форме балки с надрезом по пропорциям стандарта и имели длину $25 \mathrm{~mm}$, высоту $5 \mathrm{~mm}$, ширину $2.5 \mathrm{~mm}$ и длину надреза $0.6 \mathrm{~mm}$. Усталостная трещина создавалась при нагружении образца до $300 \mathrm{~N}$ с последующими колебаниями с амплитудой $200 \mathrm{~N}$ (асимметрия цикла $R=0.2$ ) и частотой $50 \mathrm{~Hz}$ до достижения количества циклов $7 \cdot 10^{4}$. Длина усталостной трещины составляла $0.3-0.5 \mathrm{~mm}$. При испытаниях на трещиностойкость задавалась скорость перемещения траверсы $0.02 \mathrm{~mm} / \mathrm{s}$, а прогиб балки и раскрытие трещины регистрировались с помощью бесконтактного оптического измерения по методике корреляции цифровых изображений (Digital Image Correlation) [19]. 
$a$
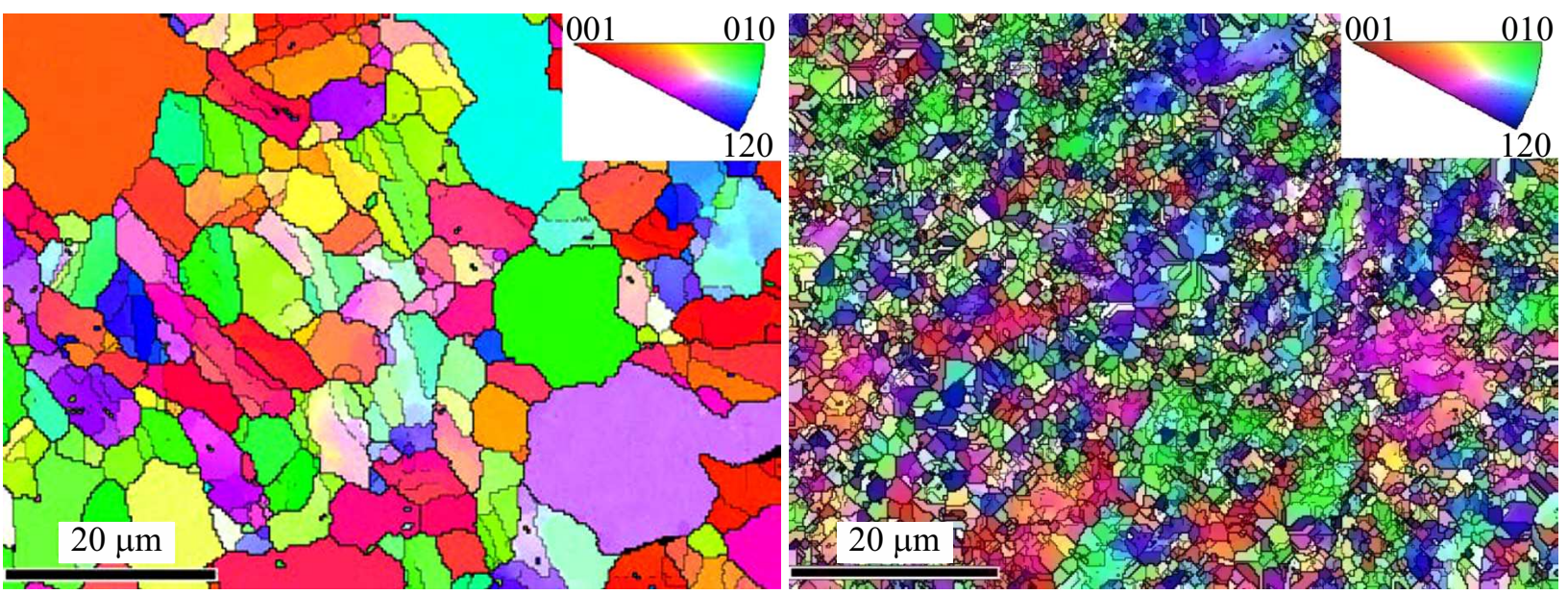

Pис. 2. Карты микроструктуры титана Grade 4 с указанием ориентировок зерен, построенные с помощью EBSD-анализа. Поперечное сечение стержней: $a$ - до РКУП-обработки; $b-$ после РКУП-обработки.

Таблица 2. Характеристики материала титана Grade 4 до и после обработки по методу РКУП-Конформ

\begin{tabular}{c|cc}
\hline Характеристика материала & До РКУП-К & После РКУП-К \\
\hline Средний размер зерна в поперечном направлении стержня $d_{t r}, \mu \mathrm{m}$ & 7.6 & 0.7 \\
Средний размер зерна в продольном направлении стержня $d_{l o n}, \mu \mathrm{m}$ & 12 & 2 \\
Микротвердость в поперечном сечении стержня $\mathrm{HV}_{t r}$ & $234 \pm 7$ & $268 \pm 21$ \\
Микротвердость в продольном направлении стержня $\mathrm{HV}_{l o n}$ & $243 \pm 15$ & $317 \pm 12$ \\
Плотность $\rho, \mathrm{kg} / \mathrm{m}^{3}$ & $4545 \pm 15$ & $4534 \pm 10$ \\
Скорость звука $c, \mathrm{~m} / \mathrm{s}$ & $6104 \pm 23$ & $6110 \pm 20$
\end{tabular}

Видео записывалось с помощью камеры с объективом для микросъемки, а анализ изображений проводился в профессиональном программном обеспечении.

Получение картин дифракция отраженных электронов (EBSD) проводилась на микроскопе Zeiss Merlin с приставкой Oxford Instruments CHANNEL5. Сканирующая электронная микроскопия поверхности разрушения проводилась на микроскопе Zeiss AURIGA Laser.

\section{2. Результаты и их обсуждение}

\section{1. Микроструктура и параметры материала}

Характеристики материала даны в табл. 2. Согласно результатам EBSD-анализа, размер зерна после обработки РКУП-К уменьшился на порядок (рис. 2). Для обоих состояний структуры материала характерно хаотичное распределение ориентировок зерен. При этом удлиненность зерен в направлении протягивания стержня существенно сказывается на микротвердости материала в поперечном и продольном направлениях стрежня. Однако небольшая погрешность измерений микротвердости говорит о достаточной однородности материала по площади поперечного или продольного сечения.

\section{2. Испытания на одноосное растяжение}

Типичные диаграммы испытаний на растяжение представлены на рис. 3. После обработки по методу РКУП-К прочность материала на разрыв возросла в 1.5 раза, но относительное удлинение снизилось более чем на треть (табл. 3). При этом полученное относительное удлинение материала после ИПД остается больше минимально допустимого относительного удлинении для коммерческого титана Grade 4-15\%.

Площадь под графиком деформация-напряжение позволяет оценить поглощение энергии до заданной степени деформации. В табл. 3 представлены значения удельной энергии деформации, которые были определены для инженерной диаграммы деформация-напряжение. Для достижения передела текучести в УМЗ титане требуется энергия в несколько раз больше, чем для крупнозернистого (КЗ) титана. Однако К3-материал поглощает существенно больше энергии как до достижения деформации с максимальным напряжением, так и до полного разрыва образца.

Изменение предела текучести $\sigma_{0.2}$ и микротвердости $H V$ с уменьшением размера зерна может быть рассчита- 
Таблица 3. Результаты испытаний материала до и после РКУП-К обработки на квазистатическое растяжение

\begin{tabular}{c|c|c|c|c|c}
\hline Материал & $\sigma_{\mathrm{UTS}}, \mathrm{MPa}$ & $\sigma_{0.2}, \mathrm{MPa}$ & $U_{R}, \mathrm{MJ} / \mathrm{m}^{3}$ & $U_{M}, \mathrm{MJ} / \mathrm{m}^{3}$ & $U_{T}, \mathrm{MJ} / \mathrm{m}^{3}$ \\
\hline До РКУП-К & $685 \pm 6$ & $514 \pm 5$ & $2.4 \pm 0.1$ & $15.3 \pm 1.2$ & $137.0 \pm 4.3$ \\
После РКУП-К & $1004 \pm 11$ & $991 \pm 16$ & $6.9 \pm 0.3$ & $94.6 \pm 1.3$ & $172.1 \pm 2.1$
\end{tabular}

Примечание: $\sigma_{\mathrm{UTS}}-$ предел прочности при растяжении; $\sigma_{0.2}-$ условный предел текучести $(0.2 \%) ; U_{R}-$ удельная работа деформации до достижения условного предела текучести; $U_{M}$ - удельная работа деформации до достижения предела прочности; $U_{T}-$ удельная работа деформации до полного разрыва образца.

но с помощью соотношения Холла-Петча [20,21]:

$$
\begin{aligned}
& \sigma_{0.2}=\sigma_{0}+k d^{-0.5}, \\
& H V=H V_{0}+t d^{-0.5},
\end{aligned}
$$

где $d$ - средний размер зерна, $\sigma_{0}$ и $H V_{0}-$ условные значения предела текучести и микротвердости для монокристалла соответственно, $k$ и $t-$ коэффициенты Холла-Петча. Решая системы уравнений для известных размеров зерна и соответствующих значений пределов текучести и микротвердости, можно определить условные константы уравнений

$$
\begin{gathered}
\sigma_{0}=306 \mathrm{MPa}, \quad k=0.573 \mathrm{MPa} \cdot \mathrm{m}^{0.5}, \\
H V_{0}=211, \quad t=0.889 \mathrm{MPa} \cdot \mathrm{m}^{0.5} .
\end{gathered}
$$

На рис. 4 показано соотношения пределов текучести и микротвердости для двух состояний структуры. Известно, что в случае металлов значения $\sigma_{0.2}$ и $H V$ могут быть связаны соотношением [22]:

$$
H V=C \sigma_{0.2},
$$

где $C$ - коэффициент, обычно близкий к трем. Однако в данном случае наблюдается отклонение для двух разных состояний структуры титана. Так, для УМЗ-состояния коэффициент равен 3.1, а для К3 - 4.6. Это может говорить о различных деформационных механизмах для данных состояний материала.

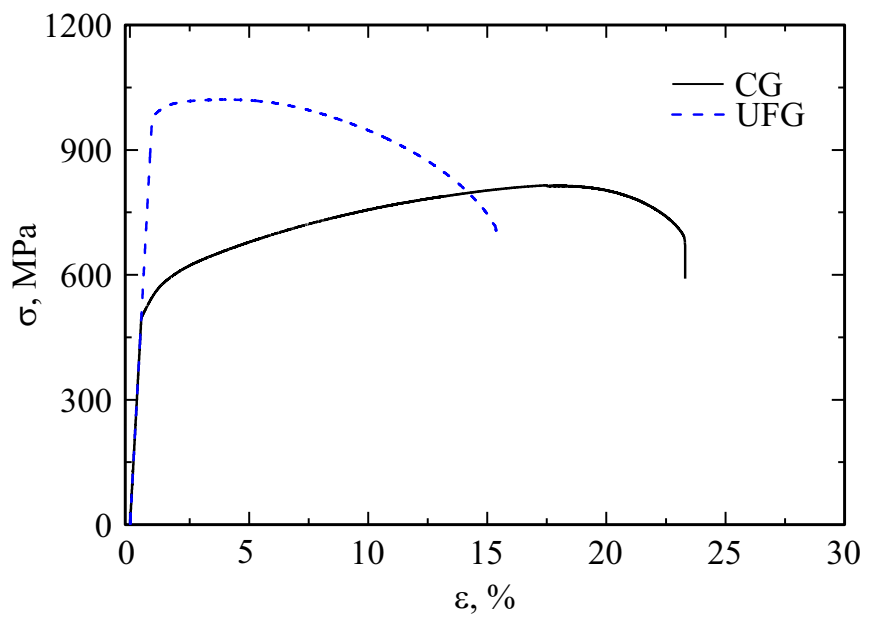

Pис. 3. Диаграмма истинных напряжений и деформации при испытаниях титана марки Grade 4 на растяжение. CG - К3состояние. UFG - УМЗ-состояние, полученное по методу РКУП-К.

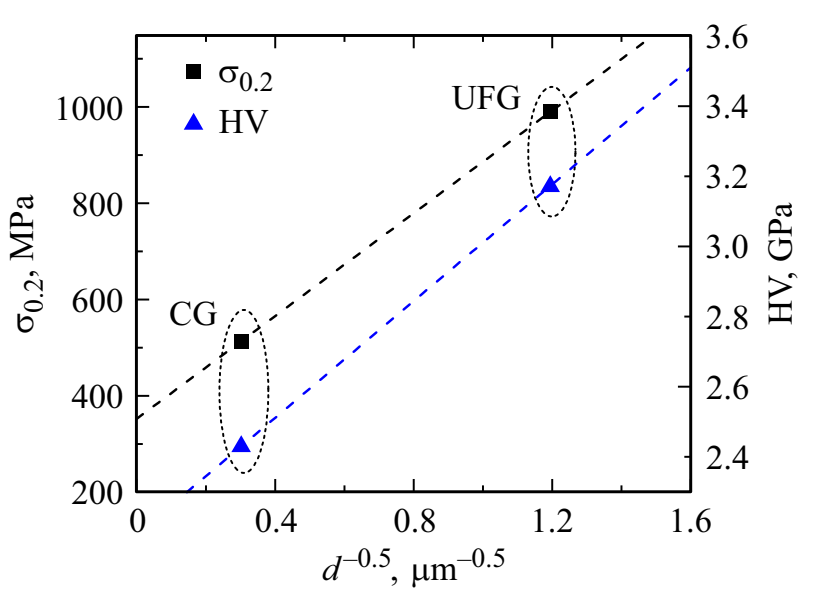

Рис. 4. Значения предела текучести и микротвердости для различных размеров зерна. Штриховая линия - расчет по соотношениям (1) и параметрам (2). CG и UFG - значения для КЗ- и УМЗ-состояний соответственно.

Таблица 4. Результаты испытаний материала до и после РКУП-К обработки на ударную вязкость по схеме Шарпи

\begin{tabular}{c|c|c|c}
\hline Материал & $\mathrm{KCU}^{*}, \mathrm{~kJ} / \mathrm{m}^{2}$ & $\mathrm{KCU}_{F r}, \mathrm{~kJ} / \mathrm{m}^{2}$ & $\mathrm{KCU}_{\text {Full }}, \mathrm{kJ} / \mathrm{m}^{2}$ \\
\hline До РКУП-К & $172 \pm 9$ & $319 \pm 13$ & $491 \pm 22$ \\
После РКУП-К & $198 \pm 26$ & $201 \pm 17$ & $399 \pm 43$
\end{tabular}

Примечание: KCU* — удельная работа до начала разрушения; $\mathrm{KCU}_{F r}$ - удельная работа от начала разрушения; $\mathrm{KCU}_{F u l l}$ - полная удельная работа.

\section{3. Испытания на ударную вязкость}

При испытаниях на ударную вязкость KCU с помощью системы датчиков и программного обеспечения копра регистрировались временной профиль нагрузки на образец и работы деформации (рис. 5). На приведенных диаграммах на начальном участке происходит рост нагрузки, а после того как напряжения в образце достигают предельного значения (момент $t^{*}$ на рис. 5), материал начинает разрушаться с продвижением макротрещины вдоль оси удара, при этом образование и развитие микро- и макродефектов приводит к существенному снижению сопротивления образца нагрузке. Таким образом, зная момент начала разрушения, можно определить как работу до разрушения, так и работу, затраченную на разрушение (табл. 4). 


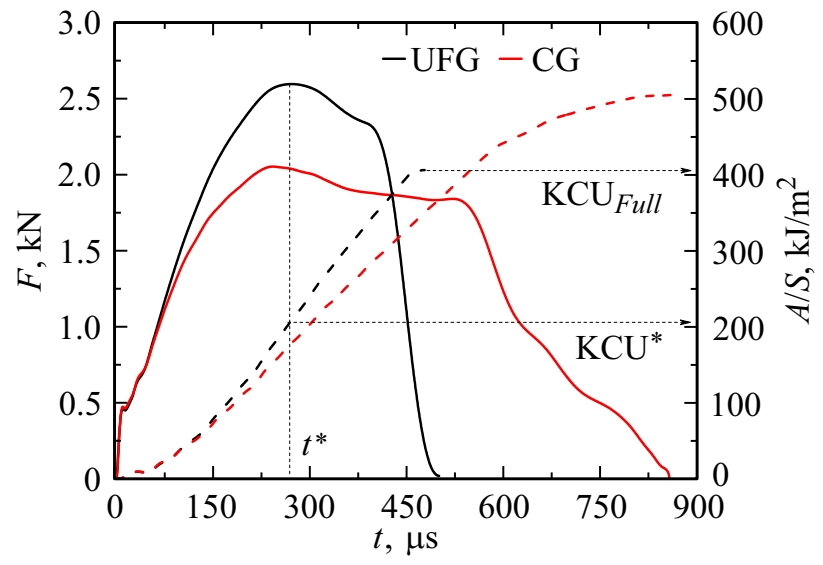

Рис. 5. Диаграммы испытаний КЗ (CG) и УМЗ (UFG) титана Grade 4 на ударную вязкость для образцов с концентратором вида $U$. Сплошные кривые - усилие; штрих - работа $A$, отнесенная к площади сечения образца $S$. На примере УМЗ титана показан способ определения ударной вязкости.

Ударная вязкость УМЗ титана оказалась на 15\% больше ударной вязкости его исходного КЗ-аналога. При этом на разрушение КЗ-материала затрачивалось в 1.5 раза больше энергии (работы после момента $t^{*}$, отнесенной к площади исходного сечения в месте удара).

\section{3. Испытания на трещиностойкость}

На рис. 6 представлены типичные диаграммы сила-перемещение точки нагружения для испытаний титана до и после обработки РКУП-К на трещиностойкость при трехточечном изгибе балки с надрезом. Как и в случае с ударной вязкостью, начало продвижения трещины соответствует началу снижения нагрузки. Согласно условной классификации, оба разрушения можно отнести к классу хрупкого/квазихрупкого разрушения [18,23]. Продвижение трещины в УМЗматериале начинается на стадии упругой деформации, в КЗ-материале развитие трещины начинается на стадии перехода упругой деформации к пластической.

Критический коэффициент напряжений $K_{I C}$ был рассчитан, согласно стандарту ASTM [18], по формуле

$$
\begin{gathered}
K_{1}=\left[\frac{F S}{B W^{3 / 2}}\right] f(a / W), \\
f(a / W)=3(a / W)^{0.5} \times \\
\frac{1.99-(a / W)(1-a / W)\left(2.15-3.93(a / W)+2.7(a / W)^{2}\right)}{2(1+2 a / W)(1-a / W)^{3 / 2}},
\end{gathered}
$$

где $F$ - усилие, действующее на образец, $S-$ расстояние между опорами, $B$ - толщина образца, $W-$ ширина образца от верхней до нижней грани, $a$ начальная трещина (надрез плюс усталостная трещина). Результаты расчетов представлены в табл. 5 .
Использование формулы (4) подразумевает выполнение в области вершины трещины условий плоской деформации, поскольку только в этом случае наблюдается отсутствие влияния размеров образца на постоянство значения $K_{I C}$. Чтобы обеспечить условия плоской деформации стандарт предполагает выполнение условия:

$$
B, W-a \geq 2.5\left(\frac{K_{I C}}{\sigma_{0.2}}\right)^{2} .
$$

Условие (5) позволяет обеспечить пластическую зону у вершины трещины много меньше размеров образца и рассматривать аппарат линейной механики разрушения. Однако данное требование удовлетворяется только для случая УМЗ титана - $2.6 \mathrm{~mm}$. В случае КЗ-материала необходимая толщина $(21 \mathrm{~mm})$ в 8 раз больше рассматриваемой. Отсюда возникает вопрос о размерном соответствии образцов и параметров рассматриваемых материалов. Производство достаточно объемных заготовок УМЗ титана требует мощного оборудования для РКУП-К, которое на данный момент имеется лишь в небольшом числе научных лабораторий. При этом для испытаний КЗ титана требуются такие размеры образцов, что доступные размеры заготовок УМЗ титана не подходят. Таким образом, нужно выбирать между сравнением результатов, которые удовлетворяют требованиям существующих стандартов, либо результатов, которые были получены для образцов с одинаковыми размерами.

Стоит отметить, что задача влияния размерных и масштабных эффектов на характеристики разрушения еще находится на стадии дискуссий. Необходима разработка подходов, которые позволят анализировать многомасштабную природу разрушения и определять параметры прочности материала для заданного масштабного уровня (например, размеры реальной конструкции) на основе

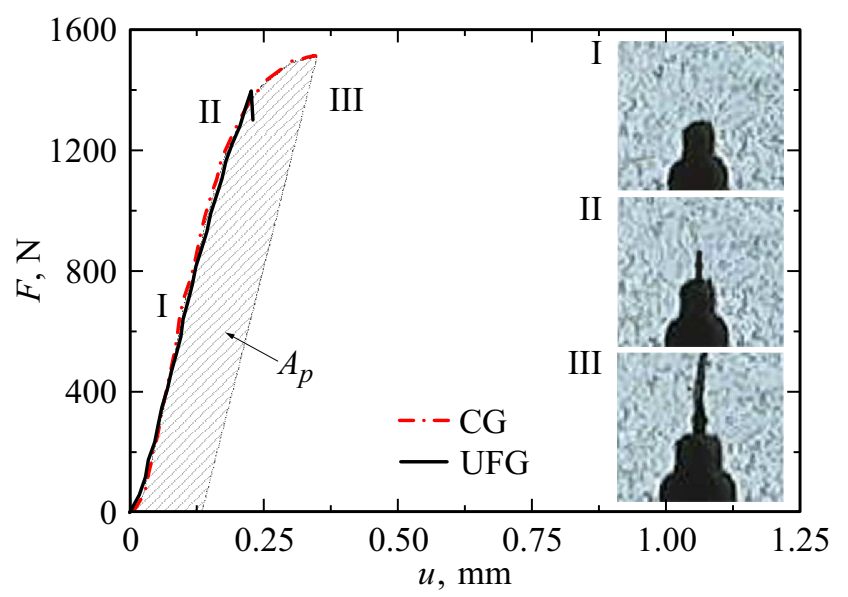

Рис. 6. Типичные диаграммы нагрузка - перемещение точки приложения нагрузки при испытаниях К3 (CG) и УМЗ (UFG) титана Grade 4 на трещиностойкость при трехточечном изгибе балки с надрезом. I - вид вершины надреза на начальной стадии упругой деформации; II - стадия видимого раскрытия усталостной трещины; III - стадия распространения трещины. 
Таблица 5. Параметры трещиностойкости титана Grade 4 до и после РКУП-К-обработки

\begin{tabular}{c|c|c|c|c|c}
\hline Материал & $K_{I C}, \mathrm{MPa} \cdot \mathrm{m}^{0.5}$ & $K_{I C}^{\Delta}, \mathrm{MPa} \cdot \mathrm{m}^{0.5}$ & $J_{C}, \mathrm{~kJ} / \mathrm{m}^{2}$ & $\delta_{m}, \mu \mathrm{m}$ & $\delta_{C}, \mu \mathrm{m}$ \\
\hline До РКУП-К & $48.9 \pm 4$ & $123.5 \pm 34.7$ & $60 \pm 21$ & $53.2 \pm 11$ & $58.5 \pm 21$ \\
После РКУП-К & $32.6 \pm 7$ & $36.8 \pm 12$ & $9.3 \pm 4.6$ & $12.5 \pm 5$ & $6.6 \pm 3.2$
\end{tabular}

экспериментальных результатов, полученных на других масштабных уровнях (например, размеры лабораторных образцов) деформации и разрушения [24].

В случае квазихрупкого разрушения одним из способов учета влияния пластической деформации на значение $K_{I C}$ является поправка длины начальной трещины на половину длины пластической зоны в направлении трещины $[23,25]$ :

$$
r_{p}=\frac{K_{I C}^{2}}{t \pi \sigma_{0.2}^{2}},
$$

где значение $t$ зависит от напряженнодеформированного состояния, принятых предположений и геометрии образца, например, $t=2$ при плоском напряженном состоянии и $t=6$ в случае объемного напряженного состояния при плоской деформации. Таким образом, заменяя начальную длину трещины а на фиктивную длину $a+r_{p}$ в выражении (4), учитывается влияние повышенной податливости в зоне вершины трещины, но решение остается справедливым для упругого поля. Результат такой подстановки для $t=2$ представлен в табл. 5. Видно, что для УМЗ-материала поправка не дала существенного изменения, но в случае К3-материала значение критического коэффициента интенсивности напряжений изменилось в 2.5 раза. Тем не менее правомерность такой подстановки остается под вопросом, поскольку пластическая зона, рассчитанная по формуле (6), сравнима с размерами образца.

Таким образом, значения $K_{I C}$ позволяют охарактеризовать трещиностойкость материала только при малой пластической зоне у вершины трещины. При наличии достаточно большой пластической деформации более представительными характеристиками трещиностойкости материала являются критическое значение $J$ интеграла $J_{C}$ или критическое раскрытие трещины $\delta_{C}$.

$J$-интеграл может быть рассчитан по формуле $[18,26]$

$$
J=J_{e}+J_{p}=\frac{K_{1}\left(1-v^{2}\right)}{E}+\frac{2 A_{p}}{B(W-a)},
$$

где $J_{e}$ и $J_{p}-$ упругая и пластическая компоненты $J$, $v$ - коэффициент Пуассона, $E-$ модуль упругости, $K_{I}$ рассчитывается по формуле (4), а $A_{p}$ - площадь под кривой на рис. 6. Результаты расчета представлены в табл. 5. В расчете критического значения $J$-интеграла $J_{C}$ для материала после обработки РКУП-К участвует только упругая компонента, а для материала до обработки РКУП-К пластическая компонента вносит существенный вклад в общую величину $J_{C}$.

Для определения раскрытия трещины (CTOD) хорошо зарекомендовал себя способ регистрации раскрытия усталостной трещины у вершины надреза с помощью измерения перемещения точек на поверхности образца между трещиной [27]. В данном способе для измерения CTOD используется специальный инструмент, который позволяет записывать смещение двух игольчатых контактов с образцом. Прямое измерение перемещения точек поверхности исключает необходимость введения калибровочных функций, которые необходимо учитывать при использовании консольного датчика [18].

Метод корреляции цифровых изображений (КЦИ) позволяет не только бесконтактно с образцом проследить перемещение каждой точки образца в процессе деформации, но и определить раскрытие усталостной трещины (рис. 6). Такой способ определения CTOD еще не получил всеобщего применения в стандартных испытаниях, но успешно применяется в исследовательских работах [28,29 и их ссылки].

В настоящей работе в качестве значения критического раскрытия трещины рассматривается значение раскрытия трещины в момент начала снижения нагрузки $\delta_{m}$ (рис. 6). Результаты измерений представлены в табл. 5.

Связь между $J$-интегралом и CTOD может быть представлена выражением [18,26]:

$$
\delta=\frac{J}{m \sigma_{Y}}
$$

где $J-$ интеграл вычисляется по формуле (7), $\sigma_{Y}=0.5\left(\sigma_{\mathrm{UTS}}+\sigma_{0.2}\right)$, а коэффициент т зависит от материала и геометрии образца $[18,26]$, в данном случае $m=1.42$ для УМЗ-материала и $m=1.72$ для К3-материала. Соответствующее расчетное критическое значение CTOD $\delta_{C}$ дано в табл. 5. Измеренное значение $\delta_{m}$ и расчетное значение $\delta_{C}$ достаточно близки.

\section{1. Поверхность разрушения}

На рис. 7 представлены поверхности разрушения рассматриваемых материалов после испытаний на растяжение, ударную вязкость и трещиностойкость. Данные снимки были сделаны в центральной части поверхности изломов. Для обоих материалов для всех случаев испытаний наблюдается преимущественно ямочный характер разрушения, что говорит о выраженной пластической деформации [30,31].

Под действием нагрузки в материале зарождаются микропустоты. Источниками зарождения микропустоты являются границы между матрицей и примесями, границы зерен, а также микротрещины и микропоры. Пустоты в материале увеличиваются под нагрузкой, 

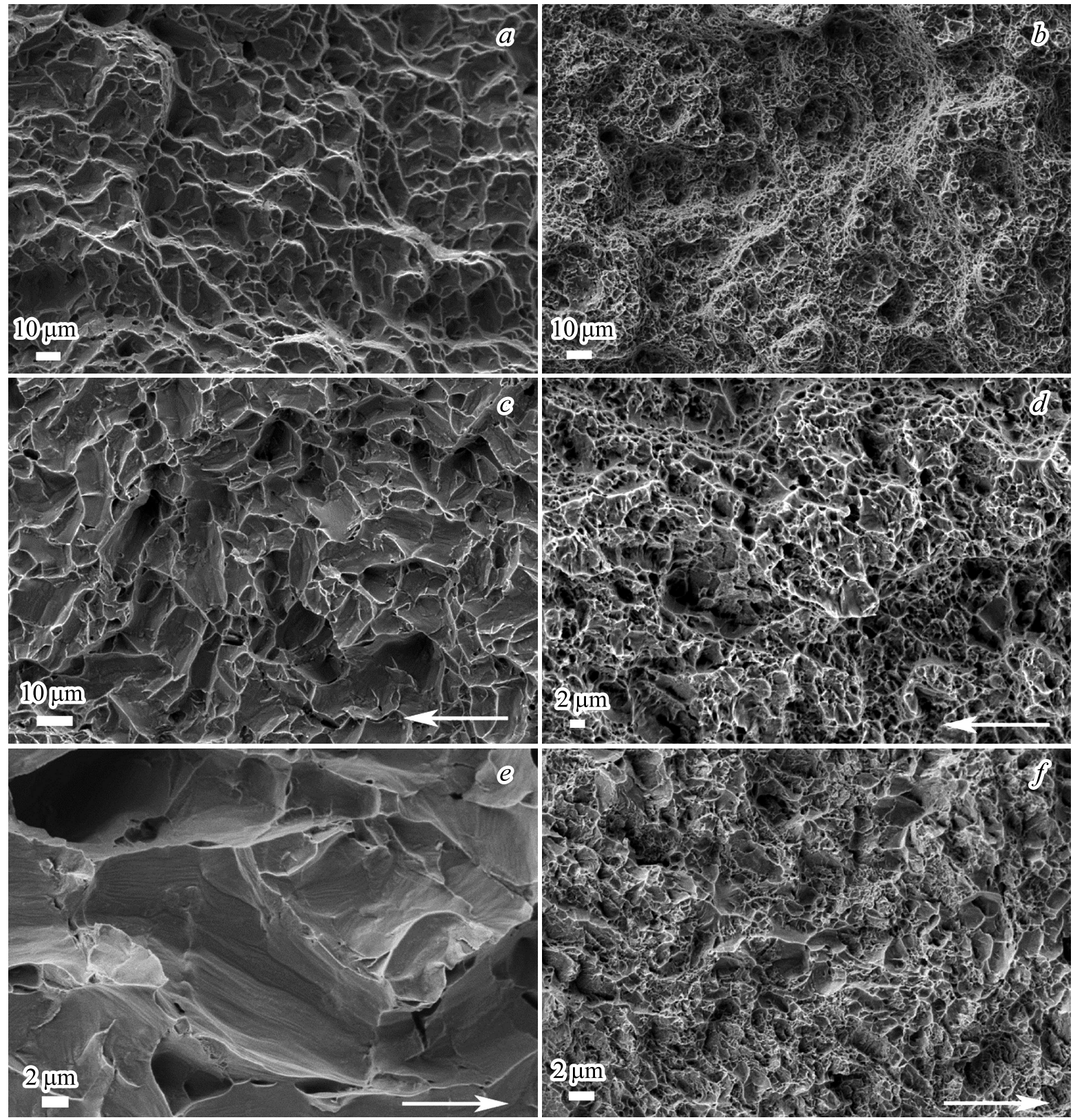

Рис. 7. Снимки СЭМ в центральной части поверхности разрушения титана Grade 4 до $(a, c, e)$ и после $(b, d, f)$ обработки РКУП-К при различных испытаниях. $a$ и $b-$ испытание на одноосное растяжение; $c$ и $d-$ испытание на ударную вязкость; $e$ и $f-$ испытание на трещиностойкость. Стрелка указывает направление продвижения трещины.

и в результате пластической деформации между ними образуются шейки, в которых материал разрывается. Форма и глубина ямок связана с плотностью источников микропустот и расстоянием между ними, а также схемой напряженного состояния. Таким образом, даже в случае квазихрупкого макроповедения УМЗ-материала при испытаниях на трещиностойкость его разрушение сопровождается локализованной пластической деформацией. Похожие картины разрушения наблюдается при разрушении УМЗ титана Grade 2 [14] и Grade 5 [32].

На рис. 7, $a, b$ представлена фрактография материалов при испытаниях на растяжение. На поверхностях разру- шения наблюдается типичное для КЗ титана вязкое разрушение с одноосными ямками различного размера [31]. При этом размер ямок УМЗ-материала существенно меньше размера ямок К3-материала. Внешний вид ямок слегка искажен в результате съемки под углом для обеспечения лучшего контраста.

Поверхности разрушения при испытаниях на ударную вязкость приведены на рис. 7, $c, d$, а на трещиностойкость на рис. 7, $e, f$. Оба состояния структуры материала демонстрируют похожую фрактографию для двух типов испытаний, что может быть связано с одинаковой схемой нагружения образцов в виде балок с надрезом. Однако 
Таблица 6. Средний размер ямок вязкого разрушения на поверхности КЗ и УМЗ титана при различных испытаниях

\begin{tabular}{clll}
\hline Материал & $F T$ & $K C$ & \multicolumn{1}{c}{$T$} \\
\hline До РКУП-К & 8.1 & 12.6 & 6.8 \\
После РКУП-К & 0.54 & 1.74 & 1.82
\end{tabular}

Примечание: $F T$ - испытание на трещиностойкость; $K C-$ испытание на ударную вязкость; $T-$ испытание на одноосное растяжение. Размеры даны в $\mu \mathrm{m}$.

между собой они отличаются уже не только размерами ямок и гребней отрыва. УМЗ-материал, как и в случае испытаний на растяжение, имеет преимущественно округленные ямки с вытянутыми границами в направлении разрыва, тогда как К3-материал имеет более угловатые и удлиненные в одном направлении формы ямок. При этом направления удлинения ямок относительно продвижения трещины расположены хаотично.

Свободная поверхность в КЗ-материале, вероятно, образуется за счет пластической деформации, которая проявляется на стенках ямок в виде ступенек скольжения (рис. $7, e$ ) со средней шириной $\sim 125 \mathrm{~nm}$. Такое серпантинное скольжение может быть обусловлено возникновением новых свободных поверхностей в результате скольжения по серии почти параллельных благоприятно ориентированных плоскостей [30].

Похожие угловатые ямки с серпантинной поверхностью скольжения, но окруженные областью более мелких ямок, встречаются и на поверхности разрушения УМ3-материала (рис. 7, $d, f$ ).

Отдельно отметим, что на всех поверхностях разрушения помимо ямок различного размера на снимках хорошо видны пустоты, глубина которых существенно превышает глубину ямок.

В табл. 6 представлены средние размеры ямок для различных типов испытаний. Размеры (расстояние от края до противоположного края ямки) были определены по методу секущих. Значения среднего размера ямок для каждого из состояний материала достаточно близки и сопоставимы со средним размером зерна в поперечном сечении образцов, в котором проходило разрушение.

\section{Заключение}

По результатам исследований можно сделать следующие основные выводы.

При высокой прочности на разрыв и приемлемом удлинении до разрыва, пластических свойств УМЗ титана недостаточно для обеспечения сопротивляемости материала старту и распространению трещины на уровне его исходного КЗ-состояния. Титан после обработки РКУП показал значение ударной вязкости KCU не хуже значения для исходного материала до обработки. Однако энергетические затраты на процесс разрушения и, как следствие, полные энергетические затраты на весь процесс деформации и разрушения у УМЗ титана оказались существенно ниже.

Такие характеристики трещиностойкости (I моды), как критический коэффициент интенсивности напряжений, критический $J$-интеграл и критическое раскрытие трещины у материала после обработки РКУП оказались существенно ниже, чем у материала до обработки. В первую очередь это может быть связано с более большой областью пластической деформации в вершине трещины КЗ-материала. Кроме того, анализ результатов показал, что необходима доработка методик испытаний миниобразцов для возможности адекватного сравнения параметров трещиностойкости КЗ- и УМЗ-материалов.

Для обоих состояний структуры материала при всех испытаниях поверхность разрушения демонстрирует преимущественно вязкое ямочное разрушение, что связано с локализованной пластической деформацией. Наличие пластической деформации говорит о потенциальной возможности повышения параметров трещиностойкости УМЗ титана.

Таким образом, совокупность конструкционных прочностных параметров УМ3-состояния титана Grade 4 указывает на его пока неоднозначное преимущество перед КЗ-состоянием. Необходим поиск микроструктурных особенностей, а также соответствующих режимов комбинации интенсивной пластической деформации и термообработки, которые позволят получить не только оптимальное сочетание высокой прочности на разрыв и относительного удлинения УМЗ титана, но и характеристик трещиностойкости не ниже, чем у КЗ титана.

Автор выражает благодарность И.П. Семеновой (УГАТУ) за предоставленный материал и А.В. Полякову (УГАТУ) за описание режимов обработки материала. Сканирующая электронная микроскопия (В.Д. Калганов) и дифракция отраженных электронов (О.С. Медведев) проводились на оборудовании Междисциплинарного ресурсного центра по направлению „Нанотехнологии“ Научного парка СПбГУ. Испытания материалов проводились на оборудовании ресурсного центра „Центр исследования экстремальных состояний материалов и конструкций“ Научного парка СПбГУ. Исследования выполнялись в рамках гранта президента РФ для государственной поддержки молодых российских ученых № МК-2587.2017.1 и гранта СПбГУ № 26130576.

\section{Список литературы}

[1] Gleiter H. // Prog. Mater. Sci. 1989. Vol. 33. P. 223-315. DOI: $10.1016 / 0079-6425(89) 90001-7$

[2] Meyers M.A., Mishra A., Benson D.J. // Prog. Mater. Sci. 2006. Vol. 51. P. 427-556. DOI: 10.1016/j.pmatsci.2005.08.003

[3] Валиев Р.З., Жиляев А.П., Лэнгдон Т.Джс. Объемные наноструктурные материалы: Фундаментальные основы и применения. СПб.: Эко-Вектов, 2017. 479 с. [Valiev R.Z., Zhilyaev A.P., Langdon T.G. Bulk nanostructured materials: fundamentals and applications. John Wiley \& Sons, New Jersey, 2014. 456 p. DOI: 10.1002/9781118742679] 
[4] Gleiter H. // Acta Mater. 2000. Vol. 48. P. 1-29. DOI: $10.1016 / \mathrm{S} 1359-6454(99) 00285-2$

[5] Zhu Y.T., Lowe T.C., Langdon T.G. // Scripta Mater. 2004. Vol. 51. P. 825-830. DOI: 10.1016/j.scriptamat.2004.05.006

[6] Valiev R.Z., Estrin Yu., Horita Z., Langdon T.G., Zehetbauer M.J., Zhu Y.T. // JOM-J. Min. Met. Mat. S. 2016. Vol. 68. P. 1216-1226. DOI: 10.1007/s11837-016-1820-6

[7] Valiev R.Z., Langdon T.G. // Prog. Mater. Sci. 2006. Vol. 51. P. 881-981. DOI: 10.1016/j.pmatsci.2006.02.003

[8] Edalati K., Horita Z. // Mat. Sci. Eng. A. 2016. Vol. 652. P. 325-352. DOI: 10.1016/j.msea.2015.11.074

[9] Sergueeva A.V., Stolyarov V.V., Valiev R.Z., Mukherjee A.K. // Scripta Mater. 2001. Vol. 45. P. 747-752. DOI: 10.1016/S1359-6462(01)01089-2

[10] Semenova I.P., Valiev R.Z., Yakushina E.B., Salimgareeva G.H., Lowe T.C. // J. Mater. Sci. 2008. Vol. 43. P. 7354-7359. DOI: 10.1007/s10853-008-2984-4

[11] Pippan R., Hohenwarter A. // Mater. Res. Lett. 2016. Vol. 4. P. 127-136. DOI:10.1080/21663831.2016.1166403

[12] Semenova I.P., Polyakov A.V., Polyakova V.V., Grishina Yu.F., Huang Yi., Valiev R.Z., Langdon T.G. // Mat. Sci. Eng. A. 2017. Vol. 696. P. 166-173. DOI: 0.1016/j.msea.2017.04.073

[13] Sabirov I., Valiev R.Z., Semenova I.P., Pippan R. // Metal. Mater. Trans. A. Vol. 41. P. 727-733. DOI: 10.1007/s11661009-0111-z

[14] Polyakov A.V., Semenova I.P., Raab G.I., Sitdikov V.D., Valiev R.Z. // Rev. Adv. Mater. Sci. 2012. Vol. 31. P. 78-84.

[15] Polyakov A.V., Semenova I.P., Huang Y., Raab G.I., Valiev R.Z., Langdon T.G. // MRS Commun. 2013. Vol. 3. P. 249-253. DOI: $10.1557 / \mathrm{mrc} .2013 .40$

[16] Semenov B.N., Smirnov I.V., Sud'enkov Yu.V. // Rev. Adv. Mater. Sci. 2016. Vol. 45. P. 52-58.

[17] ГОСТ 9454-78. Металлы. Метод испытания на ударный изгиб при пониженных, комнатной и повышенных температурах. М.: ИПК Изд-во стандартов, 1994.

[18] ASTM E1820-08. Standard Test Method for Measurement of Fracture Toughness. ASTM International West Conshohocken, PA. 2008.

[19] Jandejsek I., Gajdoš L., Šperl M., Vavř́k D. // Eng. Fract. Mech. 2017. Vol. 182. P. 607-620. DOI: 10.1016/j.engfracmech.2017.05.045

[20] Cordero Z.C., Knight B.E., Schuh C.A. // Int. Mater. Rev. 2016. Vol. 61. P. 495-512. DOI: $10.1080 / 09506608.2016 .1191808$

[21] Taha A.S., Hammad F.H. // Phys. Stat. Solid. A. 1990. Vol. 119. P. 455-462. DOI: 10.1002/pssa.2211190207

[22] Cahoon J.R., Broughton W.H., Kutzak A.R. // Metall. Trans. 1971. Vol. 2. P. 1979-1983. DOI: 10.1007/BF02913433

[23] Партон В.3., Морозов Е.М. Механика упругопластического разрушения. М.: Наука, 1985. 504 с. [Parton V.Z., Morozov E.M. Mechanics of elastic-plastic fracture. N.Y.: Hemisphere Pub. Corp., 1989. 522 p.]

[24] Petrov Y.V., Karihaloo B.L., Bratov V.V., Bragov A.M. // Int. J. Eng. Sci. 2012. Vol. 61. P. 3-9. DOI: $10.1016 /$ j.ijengsci.2012.06.004

[25] Gross D., Seelig T. Fracture Mechanics: With an introduction to micromechanics. Springer-Verlag Berlin Heidelberg, 2011. 336 p. DOI: $10.1007 / 978-3-642-19240-1$

[26] Zhu X.-K., Joyce J.A. // Eng. Fract. Mech. 2012. Vol. 85. P. 146. DOI: $10.1016 /$ j.engfracmech.2012.02.001

[27] Schwalbe K.-H. // ASTM. 1995. STP 1256. P. 763-778. DOI: $10.1520 / \mathrm{STP} 16416 \mathrm{~S}$

[28] Khor W., Moore P.L., Pisarski H.G., Haslett M., Brown C.J. // Fatigue Fract. Eng. M. 2016. Vol. 39. P. 1433-1442. DOI: $10.1111 /$ ffe. 12487
[29] Ktari A., Baccar M., Shah M., Haddar N., Ayedi H.F., RezaiAria F. // Fatigue Fract. Eng. M. 2014. Vol. 37. P. 682-694. DOI: $10.1111 / \mathrm{ffe} .12153$

[30] ASM Handbook Vol. 12. Fractography. ASM International, 1987. $517 \mathrm{p}$.

[31] Joshi V.A. Titanium Alloys: An Atlas of Structures and Fracture Features. CRC Press, 2006. 248 p.

[32] Semenova I.P., Polyakov A.V., Polyakova V.V., Grishina Yu.F., Huang Yi., Valiev R.Z., Langdon T.G. // Mat. Sci. Eng. A. 2017. Vol. 696. P. 166-173. DOI: 10.1016/j.msea.2017.04.073 